\title{
Experimental Study of Several Tools for Surface Roughness obtained using Magnetorheological Abrasive Flow Finishing Process
}

\author{
Vilas S. Kanthale* and D. W. Pande \\ Mechanical Department, MIT College Of Engineering, Savitribai Phule Pune University. Pune, India. \\ Accepted 02 March 2016, Available online 15 March 2016, Special Issue-4 (March 2016)
}

\begin{abstract}
The main objective of this work is to prepare MR fluid and investigating the various shape of flask and to determine the effect of various shape of tools on the surface of MS specimen and also verifying the stability of prepared MR fluid by using magneto rheological abrasive flow finishing process. So, in order to establish the process, the experimental set up is developed on which various trials have been conducted by considering the various shape of the tools and shape of flask. The magneto-rheological fluid consists of CI particles with mesh size 300, nonmagnetized $\mathrm{Al}_{2} \mathrm{O}_{3}$ and $\mathrm{SiC}_{\mathrm{C}}$ abrasive powder with mean sizes of 67.496 and $326.04 \mu \mathrm{m}$ respectively. Combinations of the two abrasives, Al203 and SiC, with CI particles were used with servo $4 \mathrm{~T}$ oil as a carrier fluid. It was observed that the removal rate increases with increased percentage of polishing abrasives. The relative increase depends upon the amount and type of abrasives used. Hence the improvement in surface roughness is considered as an outcome of the process.
\end{abstract}

Keywords: Fluid, Polishing Tools, Surface Roughness

\section{Introduction}

Today advanced finishing processes are the major requirements for high precision manufacturing. Sunil Jha and V. K. Jain, (2000) , (2001) has described that for most engineering parts the surface roughness plays a significant role in the service life of components. It influences the fatigue life because irregular and rough surfaces generally subjected to fatigue properties as a result of which in premature failure of the component. As surface roughness increases, many problems encountered such as resistance to flow, friction, wear \& optical loss, etc. also increase resulting in a decreased efficiency of the component. Therefore, in some application, a surface polishing operation is required during or after fabrication processes to make them suitable for performing the desired function. The conventional finishing processes such as grinding, lapping, etc. are not capable to produce the surface roughness of the order of nanometer as the complexity of the surface increases. Hence, advanced finishing processes are of prime importance for high precision components. Some advanced finishing processes based on fluid has been introduced in the last few years. These processes are very important for polishing the intricate shape of components.

One of the important aspects of finishing process is the precise control of abrading forces so that the process produces the components with close tolerances and without damaging surface topography. Therefore, the process which can control the forces in real time, are the most suitable processes for finishing different types of materials to nanometer surface roughness value. With reference to the above characteristics, magneto rheological fluid based abrasive flow finishing (MRAFF) is one of the most suitable process for finishing simple \& complex shaped as well as hard material work pieces by designing a suitable tools and setup.

The main aim of this work is to prepare magneto rheological fluid and investigating the various shape of flask and the effect of various shape of tools on the surface of specimen and also verifying the stability of prepared MR fluid. So, in order to establish the process, the experiment was carried out by considering the various shapes of the tools and shape of flask. The magneto rheological fluid consists of CI particle with mesh size 300, non magnetized $\mathrm{Al}_{2} \mathrm{O}_{3}$ and SiC abrasive powder with mean sizes of 67.496 and $326.04 \mu \mathrm{m}$ respectively. The combinations of the two abrasives, Al203 and SiC, with CI particles were used with $4 \mathrm{~T}$ oil as a carrier fluid.

\section{Literature Review}

Sunil Jha and V. K. Jain, (2000) extrapolated the developments in the micro and nano technology. The machining accuracy obtained by conventional processes would reach $1 \mu \mathrm{m}$ while in precision and ultra precision machining would reach $0.01 \mu \mathrm{m}(10$ 
$\mathrm{nm})$ and $0.001 \mu \mathrm{m}(1 \mathrm{~nm})$ respectively. Neelesh K. Jain, Vijay K.Jain, (2001).. R.Turczyn, M. Kciuk, (2008), have developed MR fluid by using three type of carriers that is silicone oil OKS 1050, synthetic oil OKS 352 and Mineral oil OKS 600 mixed with carbonyl iron powder CI HQ also, added stabilizers Aerosil 200 and 972, Arsil 1100 and Arabic gum in order to reduce the sedimentation. Results reviewed that the stability of MR fluid was improved by adding additives to the formulation and best result was achieved by Aerosil 9782. M.Kciuk,Kciuk,R.Turczyn,(2009), It was affirmed on the basis of experimental results that the dynamic viscosity of liquids increases by applying high magnetic field and also value. Sunil Jha, V.K. Jain, (2004), Atul Khatri, (2007).

Shai N. Shafrir (2007) has developed \& designed a new hybrid process called Magneto rheological abrasive flow finishing (MRAFF) process for complex internal geometries using smart magneto rheological polishing fluid. It is described that at higher magnetic flux density, abrasive marks in the direction of motion were also observed due to deep penetration of some abrasive particles in the work piece surface. Sunil Jha, V.K. Jain, (2006) studied the finite element model and which is used to find the magnetic potential distribution in the magnetic abrasive brush formed during finishing action and then it is used to evaluate machining pressure, surface finish and material removal. Sunil Jha . V. K. Jain . Ranga Komanduri, (2007) Demonstrated that MRF spots can be placed on ground nonmagnetic tungsten carbides and that are useful for analyzing the material microstructure as well as for measuring the depth of the deformed surface layer from grinding.

Sunil Jha, V.K. Jain (2007) to (2011), developed magneto rheological abrasive flow finishing process for super finishing of internal geometries of hard material. It was found that the performance of MRAFF process is mainly dependent on different parameters like MRP-fluid composition, magnetic field strength, extrusion pressure and number of finishing cycles. Also, concluded that the the best surface finish is achieved when CIPs size and abrasive particles size are almost the same. In particular, the determination of magnetic-field-induced yield stress and dynamic viscosity is important to study the flow behavior and bonding strength imparted to abrasive particles by CIP chains during finishing. Bongsu Jung et al [14] focused on the use of more effective abrasives, namely magnetizable abrasives made of iron powders sintered with carbon nano tubes for finishing aluminum oxide and titanium carbide materials.

Ajay Sidpara, V.K.Jain, (2011) to (2012) has studied the forces acting on the work piece \& also evaluated the effect of process parameters on surface roughness and material removal rate in MRF of single crystal silicon blank.. They summarized that normal and tangential forces increase with increasing CIPs concentration; however they decrease with increasing working gap and abrasive particles concentration.
Also, normal force increases with increase in wheel speed but tangential force increases up to a certain wheel speed beyond which it starts decreasing. It is concluded that, i) CIPs particle size significantly affects quality of finished surface of silicon. MRR increases with increasing CIPs size. ii) MRR increases with increasing diamond particles with increasing CIPs size from $1.1 \mu \mathrm{m}$ to $2 \mu \mathrm{m}$ however it decreases by further increase in CIPs size to $5 \mu \mathrm{m}$ and $9 \mu \mathrm{m}$. Also, by increasing the size of abrasive particles then it penetrate it into the workpiece surface as well as non uniform strength of the MR fluid ribbon created as a result of this the surface roughness decreases. iii) High yield stress of MR fluid increases MRR but at the same time it increases surface roughness too. It is revealed from the experiment that Yield stress of oil based MR fluid is lower compared to water based MR fluid which reduces the strength of MR fluid under magnetic field. Therefore, too high stiffness of MR fluid is not necessary to get good surface finish.

Ramandeep Singh and R.S. Walia (2004), have developed the new Hybrid Magnetic Force Assistant Abrasive Flow Machining Process for Optimal Material Removal. The magnetic force is generate around the full length of the cylindrical work piece by applying DC current to the solenoid, which provides the magnetic force to the abrasive particles normal to the axis of work piece

\section{Preparation of MR Fluid}

MR fluid mainly consists of magnetically iron filings / particles, non magnetized abrasive particles and a carrier fluid. As magnetic material, carbonyl iron (CI) powder having its mean size $73.84 \mu \mathrm{m}$ and volume was taken $15-30 \%$ by volume. Two non magnetized abrasive powder aluminum oxide $\left(\mathrm{Al}_{2} \mathrm{O}_{3}\right)$ and silicon carbide ( $\mathrm{SiC}$ ) was used for preparing the MR fluid.

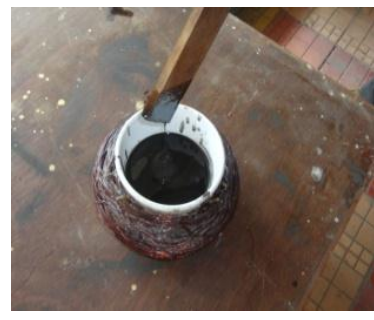

Fig. 1. MR Fluid without effect of magnetic field

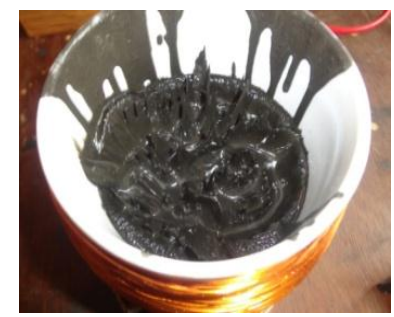

Fig. 2. MR Fluid with effect of magnetic field
The physical properties of Aluminum Oxide Powder are high hardness, low density, high wear and corrosion resistance, low thermal expansion, high strength and excellent size and shape capability. Also, Silicon Carbide physical properties are high hardness, low porosity, good wear and corrosion resistance, high thermal conductivity and superior chemical inertness. The mean sizes of these particles were $67.496 \mu \mathrm{m}$ and $326.04 \mu \mathrm{m}$ also its volume was taken $15-30 \%$ by volume respectively. The size of these entire powder 
particles was measured under microscope whose magnification factor was $14.3 \mu$.These particles were dispersed with servo $4 \mathrm{~T}$ motor oil whose volume was taken $50-60 \%$ by volume then this fluid were stirred and poured in to the experimental flask for performing the experimentation.

\section{Process Components}

\subsection{Preparation of Work piece}

A long MS black flat bar is mounted on the hydraulic hacksaw machine and work piece of dimensions $52 \mathrm{mmX} 48 \mathrm{mmX} 9.5 \mathrm{~mm}$ are cut. To study various outcomes and results for the MRAFF process certain work pieces were filed to remove the outer coating.

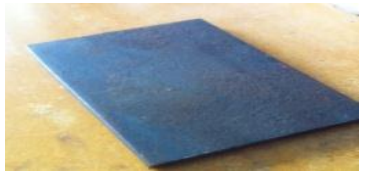

Fig. 3. M.S Work piece

\subsection{Flask \& Magnetic Field Strength}

Specifications:

1. Diameter of Flask: $0.11 \mathrm{~m}$

2. Density of Copper: $8.96^{*} 10^{3} \mathrm{~kg} / \mathrm{m}^{3}$

3. Diameter of Copper Wire: $0.406^{*} 10^{-3} \mathrm{~m}$

4. Length of Copper Wire: $1510 \mathrm{~m}$

5. Mass of Copper Wire: Density* Volume $=\left(8.96 * 10^{3}\right) *\left(0.7853 *\left(0406 * 10^{-3}\right)^{2}\right) * 1510$ $=1.7513 \mathrm{~kg}$

6. Number of Turns:(Length of Copper Wire $) /($ circumference of Flask $)=(1510) \div(0.3455)$

$$
=4370 \text { turns }
$$

7. Field Strength: $B=\mu_{0}(\mathrm{~N} \div \mathrm{L}) * \mathrm{I}$

$=0.05(4370 \div 1510) * 1.5=0.2170$ Tesla

4.3. Design of Tool:

Properties of Mild Steel:

1. Yield Tensile Strength $\left(\mathrm{S}_{\mathrm{yt}}\right): 370 \mathrm{MPa}$

2. Modulus of Elasticity (E): $205 * 10^{3} \mathrm{MPa}$

3. Factor of Safety $\left(\mathrm{N}_{\mathrm{f}}\right): 1.5$

\subsection{Calculation of crippling Load by Euler's Formula}

The column has one end fixed and other end free. Therefore the crippling load formula becomes $P=\left(\pi^{2} E I\right) \div\left(4 L^{2}\right)$

From trial and error the average diameter considering 3 steps comes to around $23 \mathrm{~mm}$ for a length of 130 $\mathrm{mm}$.

Diameter of head of the tool due to drill chuck dimension constraints is selected as $11 \mathrm{~mm}$.

Diameter of shank is considered as $22 \mathrm{~mm}$ and the diameter of tapered base is $36 \mathrm{~mm}$.

Allowable Tensile Stress $\left(\sigma_{\text {all }}\right)=\left(\mathrm{S}_{\mathrm{yt}}\right) \div\left(\mathrm{N}_{\mathrm{f}}\right)$

$$
=246.666 \mathrm{MPa}
$$

Checking for failure:

Crippling Load on Tool: $\mathrm{P}=\left(\pi^{2} \mathrm{EI}\right) \div\left(4 \mathrm{~L}^{2}\right)$

$$
=411118.6633 \mathrm{~N}
$$

Induced Stress Considering Average Diameter $(\sigma)$

$=\mathrm{P} \div \mathrm{A}=411118.6633 \div\left(4.1542 * 10^{-4}\right)$

$=98.9636 \mathrm{MPa}$

\section{Experimental Set Up}

Experiments were carried out on a pillar drilling machine (SUDARSHAN) of Standard Machine Tools Ltd. The finishing tool was mounted on the drill chuck and then used for the operation.

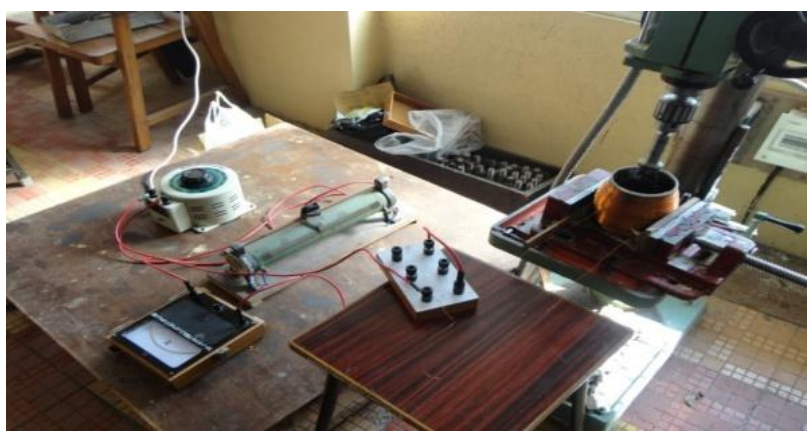

Fig. 4. Experimental setup

Experimental Procedure

1) Use winding machine, to do the copper windings on the peripheral of flask in order to get uniform windings and strength.

2) Flask is properly held in the vice. The electrical connections are given to all instruments. The dimmer stat is used to vary the voltage.

3) Pour the MR fluid prepared in the flask and make sure it doesn't spill on the coils and is mixed properly

4) Place the mild steel work piece in the flask and it is firmly fixed with the help of screw to the base of plate which is again fixed inside the flask. Again ensuring that it should not rotate along with the work piece and check that it is completely immersed in the fluid.

5) Start the drilling machine and adjust the gap between the tool and work piece such that it's big enough for the fluid to flow between them but not very big.

6) Stop the drilling machine and then make the electrical connections as show.

7) After selecting the required voltage and current again start the drilling machine to start the finishing process.

8) After a fixed time interval turn off the drilling machine and slowly reduce the voltage and current to zero so as to demagnetize the flask.

9) Wipe the work piece with a clean cloth and measure its surface roughness value.

10) Repeat the procedure for various work pieces by changing basic parameters. 


\section{Effect of Different Shape of Polishing Tools on Surface Roughness}

Various shapes of tools were prepared to get the desired surface finish which is discussed below. 6.1. Spherical joint of mirror rod:

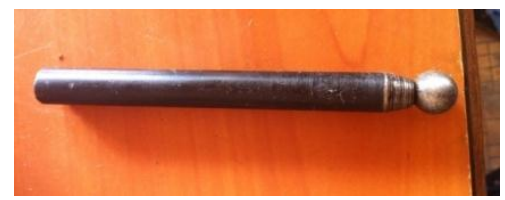

Fig. 5. Spherical ball joint tool

The spherical ball joint of the mirror rod was used as tool. The fluid is trapped between the work piece and tool is less due to less surface area of spherical tool. The main limitations of this tool is the area of finished surface obtained is less than flat surfaced tools for given no. of cycles and also centre of the spherical ball did not coincide with the axis of the tool rod.

\subsection{Circular disk welded to cylindrical rod tool}

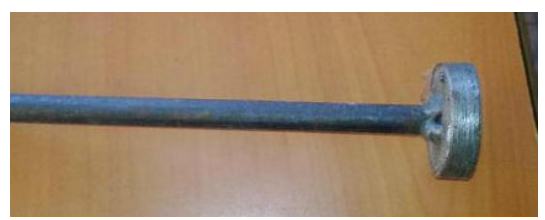

Fig . 6. Circular disc welded tool

A circular disk welded to a cylindrical MS rod was used as a tool. The flat circular face of the rod was used for the finishing process.. The main advantages of this tool are the finished surface area obtained is more and also axis of rod and circular disc did not coincide.

\subsection{Rectangular plate welded to cylindrical rod}

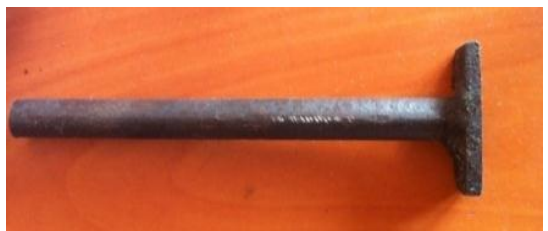

Fig. 7. Rectangular plate welded tool

A rectangular MS plate of desired cross section was cut and welded to the MS cylindrical rod. Its main advantage is the MR fluid entrapped between the work piece and tool surface is more. The finished surface area obtained is more than spherical ball tool for same no. of cycles. But, its main limitation is that centre of rectangular plate did not coincide with the cylindrical rod. Due to this misalignment, there was a wobbly motion of the tool which caused non uniform finishing of the work piece.

\subsection{Turned finishing tool}

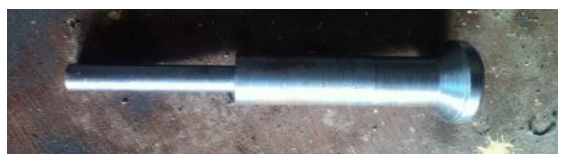

Fig. 8. Turned finishing tool

In order to overcome the problems due to misalignment of axes, the tool was machined on lathe machine. Turning and facing operations were performed to obtain the tool as shown in the above figure. Its main advantages are wobbly motions eliminated as well as MR fluid entrapped between tool and work piece is more than previously used tools so, the quality of work piece finish was better.

\section{Effect of Different Shape of Flask on Surface Roughness}

Experimentation was carried out using three types of flask. The disadvantages of the first two were over come in the third flask.

\subsection{Flask 1}

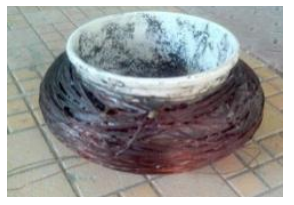

Fig.9. Flask 1

Initially, a melamine flask was obtained in which the Magneto rheological fluid, the work piece to be machined were to be placed. On this flask, copper coils of Gauge 29 and approximately 700 grams by weight were wound manually. However, it was noticed that, the field that was induced was insufficient to turn the fluid semi-solid which is essential for the finishing process.

To obtain the required magnetic field more copper coil windings were manually done on the flask. But, it was noticed that even though the strength of magnetic field was increased, excessive heat was generated. This was a result of non-uniform windings on the flask. This resulted in heating of the fluid in the flask which changed its properties. As a result, we decided to do the copper windings with the help of a winding machine on a different flask for uniformity of the windings.

We also came to the conclusion that it was necessary to increase the diameter of the copper coils to reduce the number of turns.

\subsection{Flask 2}

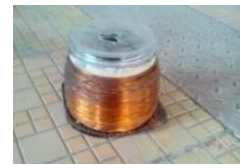

Fig.10. Flask 2 
A microwave safe flask was chosen instead of a melamine flask for the MR fluid and the work piece. The microwave safe flask was selected over a melamine flask as it doesn't heat despite passing a voltage of $220 \mathrm{~V}$. On this flask, copper coils of Gauge 27 and $1 \mathrm{~kg}$ by weight were wound with the help of a winding machine. After carrying out few trials it was observed that the surface finish was not up to the mark.

To overcome this problem, additional $1 \mathrm{~kg}$ copper windings were added with the help of a winding machine.

But due to fault the soldering the magnetic field was not created. Hence we wound new coils around a new flask.

\subsection{Flask 3:}

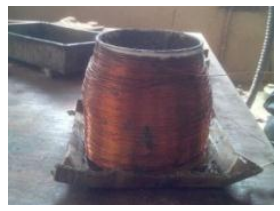

Fig. 11. Flask 3

Third flask was selected as a safe flask to overcome the disadvantages of the melamine flask. On this flask, copper coils of Gauge 27 and $2 \mathrm{~kg}$ by weight were wound with the help of a winding machine. It was observed that in this third flask, the magnetic field was much stronger compared to flask 1 and flask 2 . The surface finish in this case was also superior in comparison with the previous cases.

\section{Conclusion}

From the above experimentations and observations we conclude that the CIP is a major component for creating magneto rheological effect while addition of abrasive particles in MR fluid changes its rheological properties under the effect of magnetic field. For MRAFF process we concluded that it is preferable to use non-ferrous tools as it absorbs most of the magnetic field required to form the iron metal powder chains. $\mathrm{Al}_{2} \mathrm{O}_{3}$ is the suitable abrasive as its grains are finer than $\mathrm{SiC} . \mathrm{Al}_{2} \mathrm{O}_{3}$ gives better surface finish in some sets of trial. Also, it gives better surface finish than the surface finish obtained by surface grinding.

Tools made from multiple parts should not be deployed as its results in poor surface finish due to cumulative inaccuracies in the assembly of the parts. MRAFF can be used to finish ferrous materials using a stagnant fluid bath.

We undertook process was stochastic and it needs to be optimized with all stated parameters to make the process deterministic.

\section{References}

Sunil Jha and V. K. Jain, (2000), Nano-Finishing Techniques, Int. J Adv. Manuf. Tech 15, pp. 243-252.

Neelesh K. Jain, Vijay K.Jain, (2001), Modeling of material removal in mechanical type advanced machining processes: a state-of-art review, International Journal of Machine Tools \& Manufacture 41, pp. 1573-1635

R.Turczyn, M. Kciuk, (2008), Preparation and study of model magnetorheological fluids, Journal of AMME, Volume 27, Issue 2 , pp. 131-134.

M.Kciuk,Kciuk,R.Turczyn,(2009), Magnetorheological characterisation of carbonyl iron based suspension, Journal of AMME, Volume 33, Issue 2, pp. 135-141.

V.K. Jain, Prashant Kumar, P.K. Behera, S.C. Jayswal, (2011), Effect of working gap and Circumferential speed on the performance of magnetic abrasive finishing process, Wear 250 (2001) pp. 384 390

Dhirendra K. Singh1, V.K. Jain*, V. Raghuram, (2004), Parametric study of magnetic abrasive finishing process, Journal of Materials Processing Technology 149, pp. 22-29.

Sunil Jha, V.K. Jain, (2004), Design and development of the magnetorheological abrasive flow Finishing (MRAFF) process, International Journal of Machine Tools \& Manufacture 44, pp 1019-1029.

Amit M. Wani,Vinod Yadava, Atul Khatri, (2007), Simulation for the prediction of surface roughness in magnetic abrasive flow finishing (MAFF), Journal of Materials Processing Technology 190 , pp. 282-290.

Shai N. Shafrir, John. C. Lambropoulos a,b, Stephen D. Jacobs, (2007), A magnetorheological Precision Engineering Int J Adv Manuf Technol 31, pp. 83-93.

Sunil Jha, V.K. Jain , (2006), Modeling and simulation of surface roughness in magnetorheological abrasive flow finishing (MRAFF) process, Wear 261, pp. 856-866.

Sunil Jha . V. K. Jain . Ranga Komanduri, (2007), Effect of extrusion pressure and number of finishing cycles on surface roughness in magnetorheological abrasive flow finishing (MRAFF) process, Int J Adv Manuf Technol 33: 725-729.

Mnas Das, V.K. Jain, P.S. Ghoshdastidar, (2008), Fluid flow analysis of magnetorheological abrasive flow finishing (MRAFF) process, International Journal of Machine Tools \& Manufacture 48, pp. 415-426.

Sunil Jha,V. Jain, (2009),Rheological characterization of magnetorheological polishing fluid for MRAFF, Int J Adv Manuf Technol 42, pp. 656-668.

Bongsu Junga ,Kyung-InJang,(2009), Magnetorheological finishing process for hard materials using polishing-based approach for studying precision microground surfaces of tungsten carbides,sintered iron-CNT compound abrasives, International Journal of Machine Tools \& Manufacture 49 pp. 407-418.

Ajay Sidpara, V.K. Jain, (2011), Effect of fluid composition on nanofinishing of single crystal silicon by magnetic field assisted finishing process, Int. J Adv. Manuf. Tech 55, pp. 243-252.

Ajay Sidpara,V. K. Jain, (2011),Experimental investigations into forces during magnetorheological fluid based finishing process, International Journal of Machine Tools \& Manufacture 51, pp. 358-362.

Ajay Sidpara, V.K. Jain, (2012), Theoretical analysis of forces in magnetorheological fluid based finishing process, Int. Journal of Mechanical Sciences 56, pp. 50-59.

Ajay Sidpara, V.K. Jain, (2012), Nano-level finishing of single crystal silicon blank using magnetorheological finishing process, Tribology Int 47, pp. 159-166.

Ajay Sidpara and V. K. Jain, (2012), Experimental Investigations into Surface Roughness and Yield Stress in Magnetorheological Fluid Based Nano-finishing Process ,International Journal of Precision Engineering and Manufacturing, Vol. 13, pp. 855-860.

Ramandeep Singh and R.S. Walia, (2004), Hybrid Magnetic Force Assistant Abrasive Flow Machining Process Study for Optimal Material Removal, International Journ of Applied Engineering Research Vol.7 ,No.11.pp 1019-1029. 